\title{
Molecular biology of channel catfish brain cytochrome P450 aromatase (CYP19A2): cloning, preovulatory induction of gene expression, hormonal gene regulation and analysis of promoter region
}

\author{
Y Kazeto and J M Trant \\ Center of Marine Biotechnology, University of Maryland Biotechnology Institute, 701 East Pratt Street, Baltimore, MD 21202, USA \\ (Requests for offprints should be addressed to J M Trant; Email: trant@umbi.umd.edu)
}

\begin{abstract}
Cytochrome P450 aromatase (CYP19) converts androgens to estrogens. Unlike mammals, teleosts have two CYP19 genes, expressed differentially in ovary (CYP19A1) and neuronal tissues (CYP19A2). The primary purpose of this study was to demonstrate the potential involvement of CYP19A2 in the reproductive endocrinology of teleosts. Channel catfish CYP19A2 (ccCYP19A2) cDNAs were isolated from the brain using a PCR-based strategy. The ccCYP19A2 cDNA putatively encodes 500 amino acids which conferred aromatase activity in transfected COS-7 cells. Additionally, an alternatively spliced transcript was isolated which lacks the first 122 amino acids and is catalytically inactive. The brain and the pituitary were predominant sources of ccCYP19A2 transcript and the abundance in both tissues acutely increased prior to spawning. This preovulatory induction of ccCYP19A2 gene in the pituitary is remarkably similar to the pattern of gene expression for luteinizing hormone- $\beta$ (LH $\beta)$. Estradiol-17 $\beta\left(E_{2}\right)$ and testosterone enhanced the transcript abundance of cCCYP19A2 and LH $\beta$ in catfish pituitary cells cultured in vitro but the stimulatory effects of testosterone were abolished by an aromatase inhibitor, indicating an important role of $E_{2}$, the product of CYP19A2 activity, in the regulation of CYP19A2 and LH $\beta$. Structural and functional analysis of the $5^{\prime}$-flanking region of the gene suggested that the sequence from -1076 to $-435 \mathrm{bp}$ is critical for the basal promoter activity in the pituitary. This report demonstrates that CYP19A2 functions as an important factor in the reproductive endocrinology of teleosts through the brain-pituitary-gonadal axis.
\end{abstract}

Journal of Molecular Endocrinology (2005) 35, 571-583

\section{Introduction}

Estrogens, especially estradiol-17 $\left(\mathrm{E}_{2}\right)$, function in many physiological processes including early development, sexual differentiation, onset of puberty and reproduction in all vertebrates studied to date. In non-mammalian vertebrates, $\mathrm{E}_{2}$ is involved in numerous reproductive events, for example hepatic vitellogenin (the precursor of yolk protein) synthesis (Wallace 1985) in the liver, gametogenesis (Billard 1992) and gonadal sex determination (Wibbels et al. 1991). Therefore, the precise regulation of $\mathrm{E}_{2}$ biosynthesis, controlled primarily through the expression of genes encoding steroidogenic enzymes, is apparently required for reproductive success. Cytochrome $\mathrm{P} 450$ aromatase (CYP19) is the terminal steroidogenic enzyme in the biosynthetic pathway of $\mathrm{E}_{2}$ and is responsible for the conversion of androgens into estrogens (Simpson et al. 1994). Even though the major sources of circulating $\mathrm{E}_{2}$ in mammals are ovary and placenta, in which CYP19 gene is highly expressed, it has been well documented that some peripheral (classical non-steroidogenic) tissues, such as adipose tissue, bone and brain, express this enzyme and that the locally synthesized $\mathrm{E}_{2}$ functions in a paracrine or autocrine manner (Simpson et al. 1994).

Originally described in humans (Simpson et al. 1997), the genomes of all mammals contain a single CIP19 gene, except for the pig in which three distinct genes encode three forms of CYP19 (Graddy et al. 2000). Tissue-specific expression is controlled by the use of a variety of tissuespecific promoters associated with alternatively spliced $5^{\prime}$-untranslated exons. In contrast there is increasing evidence that most teleosts (bony fish) possess two CrP19 genes: CIP19A1, which is primarily expressed in the gonads, and CYP19A2 which is mainly expressed in the brain. (Note that through discussions with Daniel Nebert (University of Cincinnati Medical Center, Cincinnati, $\mathrm{OH}, \mathrm{USA}$ ) and David Nelson (University of Tennessee, Memphis, TN, USA), the accepted rules of nomenclature for the superfamily of cytochromes P450 dictates these designations, but they should apply to the duplicated genes of the teleosts only. This nomenclature should be substituted for the previously published designations of CYP19a and CYP19b.) These gene products have been 
identified in a widely diverse list of teleost species, including the goldfish (Tchoudakova \& Callard 1998), zebrafish (Kishida \& Callard 2001, Trant et al. 2001), rainbow trout (Valle et al. 2002), tilapia (Kwon et al. 2001) and European sea bass (Blazquez \& Piferrer 2004). Phylogenetic analyses of CYP19s isolated to date have clearly segregated the fish CIP19A1s, CYP19A2s and CYP19s from other vertebrate species into three distinct clusters (Blazquez \& Piferrer 2004). It is evident that the CYP19 genes arose through gene duplication in goldfish (Tchoudakova \& Callard 1998) and zebrafish (Kishida \& Callard 2001, Trant et al. 2001) and have since diverged in function and primary structure. These CYP19 isoforms share approximately $60 \%$ amino acid sequence identity and map to different chromosomes (Trant et al. 2001).

The brain of adult teleosts has relatively much higher aromatase activity (100-1000 times higher) than in adult mammals (Pasmanik \& Callard 1985). As suggested by the reports that neuronally derived $\mathrm{E}_{2}$ regulates neuronal differentiation, survival and function in mammals (Toran-Allerand 1996), this high level of CYP19A2 gene expression is thought to be related to the exceptional capability of the teleost brain to grow indefinitely, its neuroplasticity and its neuronal regeneration capability during adulthood (Forlano et al. 2001, Menuet et al. 2003). This hypothesis is contradicted by the fact that the rapidly growing brain of embryo/juvenile zebrafish expresses CYP19A2 poorly relative to the adult (Tong et al. 2001). Furthermore, this developmental pattern is quite different from mammals where brain aromatase activity is highest during prenatal organization and development and declines in adulthood (Lephart 1996). It has also been suggested that the expression of brain aromatase influences the brain-pituitary-gonadal axis of reproductive physiology, especially with respect to steroid feedback onto gonadotropin and/or gonadotropin-releasing hormone (GnRH) secretion (MacLusky \& Naftolin 1981, Khan et al. 1999); however, little attention has been received to address this hypothesis. In addition to the brain, the teleost pituitary highly expresses the CIP19A2 gene (Gelinas et al. 1998, Menuet et al. 2003, Goto-Kazeto et al. 2004), whereas the mammalian pituitary is generally considered aromatase-negative although the rat pituitary is known to express this enzyme (Callard et al. 1983, Carretero et al. 1999). This suggests that CYP19A2 gene may be important for the function of the pituitary gland in teleosts.

The channel catfish, Ictalurus punctatus, was selected as a model teleost species to examine the association of the CYP19A2 gene with reproduction because many components of its reproductive endocrinology are well coordinated with gonadal development, which is typical for seasonal breeders with synchronous oocyte development. The channel catfish is a teleost model species in which the reproductive physiology (ovarian steroidogenesis, the expression of four steroidogenic enzymes, both gonadotropins and their receptors, etc.) has been well studied at the molecular level (Kumar et al. 2000, 2001a, 2001b, Kumar \& Trant 2004). In this study, we characterized the channel catfish cDNAs encoding CYP19A2, the tissue distribution of expression and gene expression in the brain and the pituitary during a reproductive cycle, and examined its mode of gene regulation.

\section{Materials and methods}

\section{Animal and tissue collection}

Mature but inexperienced adult female channel catfish were directly captured from ponds of a local fish farm (Bowling Catfish Farms, Charles City, MD, USA). Up to six animals were collected at 4-week intervals for 15 months (Kumar et al. 2000). Few or no fish were available for the months from December through February because most catfish at this latitude are dormant in winter. Tissues were dissected in the field and immediately flash-frozen in liquid nitrogen. Pituitaries used for in vitro culture experiments were kept in ice-cold L-15 medium until processed. All frozen tissues were stored at $-80^{\circ} \mathrm{C}$ prior to analysis.

\section{Isolation and sequence of channel catfish CYP19A2 cDNA}

Total RNA was extracted from the whole brain of a catfish with post-vitellogenic ovaries using Trizol reagent (Life Technologies, Gaithersburg, MD, USA) and subsequently enriched for poly $\left(\mathrm{A}^{+}\right)$RNA with Straight A's mRNA Isolation System (Novagen, Madison, WI, USA). Brain cDNA was synthesized using PowerScript (BD Bioscience, Palo Alto, CA, USA) after being primed with a clamped oligo(dT) primer. PCR was carried out using a set of degenerate primers: $5^{\prime}$-CAGTG $(\mathrm{CT})(\mathrm{GA})$ T(AG)(CT)T(GA)GA(GA)ATG-3' (5' primer; P1) and 5'-TTG(GA)TCATG(AG)CG(AG)T(AG)G(CA)(ATG)A TGTG-3' (3' primer; P2). The PGR was performed at $94{ }^{\circ} \mathrm{C}$ for $30 \mathrm{~s}, 50{ }^{\circ} \mathrm{C}$ for $30 \mathrm{~s}$ and $72{ }^{\circ} \mathrm{C}$ for $30 \mathrm{~s}$ for 40 cycles. The resultant PCR products were subjected to $1 \cdot 2 \%$ agarose gel electrophoresis. A single amplicon was detected and inserted into a T/A cloning vector ( $\mathrm{pDrive;}$ Qiagen, Valencia, CA, USA) and sequenced using an ABI 373 DNA sequencer (Perkin Elmer, Foster City, CA, USA).

Based on the sequence information of the presumed channel catfish CYP19A2 (ccCYP19A2) cDNA fragment, rapid amplification of cDNA ends (RACE) reactions were performed to generate the $5^{\prime}$ - and 3'-termini using a SMART RACE cDNA Amplification kit (BD Bioscience) according to the manufacturer's instructions. Gene-specific primers used in the 5'- and 3'-RACE reactions were 5'-CCCCACACAGGCACGT 
GGTCCACAGC-3' (P3) and 5'-TGGACGGGAGGT GGAGCGGGGTGAACT-3' (P4), respectively. The RACE amplicons were subcloned and sequenced as described above. Finally, the complete open reading frames (ORFs) of ccCYP19A2 were generated by PCR with 5'-GTCAATCTTCACGGAGTTTCAGG-3' (P5) and 5'-GGGTGTTTATTGCTTGTCTGGG-3' (P6) primers using a proofreading Pfu Turbo DNA polymerase (Stratagene, La Jolla, CA, USA). Two resultant specific amplicons, designated the long and short forms of ccCYP19A2 (ccCYP19A2 and ccCYP19A2s; see the Results section), were generated and cloned into pBluescript (Stratagene), and three clones for each form were bi-directionally sequenced. As the multiple lengths of amplicons were seen when 5'-RACE PCR was conducted, the 5'-terminus regions of 15 additional clones were sequenced.

\section{Analysis of 5'-terminus of the ccCYP19A2 gene}

Catfish genomic DNA was analyzed by PCR to determine the structural relationship between multiple 5'-untranslated regions (5'-UTRs; see the Results section) and the ccCYP19A2 gene. Genomic DNA was extracted from catfish brain using a Blood \& Cell Culture DNA Starter Kit (Qiagen) and was amplified by PCR swith 5'-CGAGATCGACGACAGGCAGTGTA GAGG-3' and 5'-GTAGGGATACGTGTCGACAA-3' primers. The intron/exon boundary sites were determined by comparing the genomic sequence with the cDNA sequence obtained by 5 '-RACE.

\section{Transient expression of ccCYP19A2 in COS-7 cells}

The cDNAs containing the entire ORFs of ccCYP19A2 and ccCYP19A2s were ligated into a eukaryotic expression vector, pSI (Promega, Madison, WI, USA) and designated ccCYP19A2/pSI and ccCYP19A2s/pSI. COS-7 cells (ATCG, Manassas, VA, USA) were maintained following the ATCC's recommendations and dispensed into six-well tissue culture plates. Cells were cotransfected with a vector construct possessing the firefly luciferase gene downstream of a simian virus 40 (SV40) promoter and either ccCYP19A2/pSI, ccCYP19A2s/pSI or empty pSI using FuGENE 6 Transfection Reagent (Roche Diagnostic Corp, Indianapolis, IN, USA) according to the manufacturer's protocol. COS-7 cells transfected with the DNA constructs were incubated in complete growth medium (Dulbecco's modified Eagle's medium (DMEM) plus 10\% fetal bovine serum (FBS)) for $36 \mathrm{~h}$ and then incubated with androstenedione (30 ng/ml; Sigma, St Louis, MO, USA) in serum-free medium (DMEM, $200 \mu \mathrm{g} / \mathrm{ml} \mathrm{BSA}$ ) for 3 or $10 \mathrm{~h}$. After the incubation, media were collected and the estrone titer was measured by radioimmunoassay using a commercially available estrone RIA kit
(Diagnostic System Laboratory, Webster, TX, USA). Additionally, luciferase activity was determined in the cells by a Luciferase Assay kit (Promega) and MicroLumat LB98P luminometer (EG\&G Berthold, Stammwerk Wilbad, Germany) to verify constant transfection efficiencies in each experimental group. Three replicates of each experiment were carried out.

\section{Primary culture of catfish pituitary cells}

Channel catfish pituitary cells were maintained in primary cultured as described elsewhere (Rebers et al. 2000), with some modifications. In brief, pituitary glands were minced with a scalpel and treated with $0 \cdot 1 \%$ type I collagenase (Sigma) in $\mathrm{Ca}^{2+}$ - and $\mathrm{Mg}^{2+}$-free PBS for $2 \mathrm{~h}$ at room temperature with gentle shaking. Tissue fragments were allowed to settle for a few minutes and the supernatant was transferred into a new tube and centrifuged for $10 \mathrm{~min}$ at $200 \mathrm{~g}$. The resultant cells were washed with PBS twice and resuspended in HEPES (10 mM)-buffered L-15 medium containing 10\% charcoal-stripped FBS (Atlanta Biologicals, Norcross, GA, USA) and a $1 \%$ penicillin/streptomycin mixture (Life Technologies). Cells were plated at a density of 100000 cells/well in 48-well tissue-culture plates and incubated for $48 \mathrm{~h}$ at $25^{\circ} \mathrm{C}$ in medium supplemented with $\mathrm{E}_{2}$, testosterone $(0 \cdot 03-30 \mathrm{nM})$ or a combination of testosterone $(0,3$ and $30 \mathrm{nM}$ ) and the aromatase inhibitor 1,4,6-androstatriene3,17-dione (ATD; $10 \mu \mathrm{M}$ ). After incubation, cells were harvested, flash-frozen and stored at $-80^{\circ} \mathrm{C}$.

\section{Isolation and characterization of the $5^{\prime}$-flanking region of ccCYP19A2}

A catfish GenomeWalker library was constructed with a Universal GenomeWalker Kit (Kazeto et al. 2001; BD Bioscience) and used in a PCR-based strategy to isolate the promoter region of the ccCYP19A2 gene. Genomewalking PGRs using Advantage-GG genomic polymerase (BD Bioscience) were primed with 5'-CCCG TACGCTCGATTACAGGCATGACATC-3' and then followed with a nested second amplification using a 5'-CCTCGATTACAGCGATGACATCAGACACG-3' primer. The resulting single amplicon was T/A cloned and sequenced. Promoter analysis of the $5^{\prime}$-flanking region of the ccCYP19A2 gene was conducted at http://motif.genome.ad.jp/ with an 80\% cut-off score. Additionally, consensus core sequences for transcription factor-binding sites of interest, such as cAMP-responsive element (GRE; TKAGGTMA), estrogen-responsive element (ERE; AGGTCANNNTGACGT), glucocorticoid-/ progestin-/androgen-responsive element (ARE; AGAAC ANNNTGTTCT) and the responsive element for aryl hydrocarbon receptor and its nuclear transfer protein (AhR/Arnt; TYGGGTG) were manually searched using DNASIS-Mac v3.5 software. 
ccttcacacaaacaagacactcaagggcctcttagtctacttttagacaggttttttttttctttcaggattgttttgactgttccaat agcacaaagcctttgatttgaaggactttataaattggatggctgcctgccaaatctcttcaaatcccccttcttttcaaggaccacttc atgtgctgtcaagaagaagtacattaatataagccagaagagaaacggcgagaaatccagtgtgaggagtcgtttggctcaggtggttta P5 $\rightarrow$ agtcaatcttcacggagtttcaggATGGAGTTACAGAACGTGTCTGATGTCATGGCTGTAATGGAGGGTAGGGGATTATGTGTTATATCA The membrane spanning region

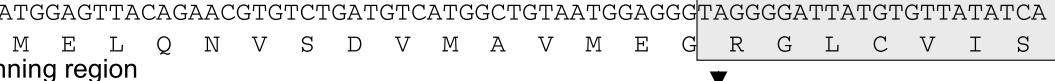
GCATTACTCTTTCTTCTACTGCTAACTTCACTTACAGCCTACAACAGAAGAAACAAATCTACCTTACCAGGTCCCTACTGGTTACTGGGG

ACATATTTTGCCAAAGCCTTAACAGGCCCTGGTCTGCAGAGGACAGTGGGTGTGTGTGTTCATGCCACCAATAAGCACTTGGATGTCCTG

$\begin{array}{lllllllllllllllllllllllllllllll}T & Y & F & A & K & A & L & T & G & P & G & L & Q & R & T & V & G & V & C & V & H & A & T & N & K & H & L & D & V & L\end{array}$

TGCGAGTTCATGGACTCCTCAGGCCATGTGGATGCTCTGAACTTCCTACGCTGCATAGTGGTCGACGTCTCCAACAGACTCTTCCTCCGA $\begin{array}{llllllllllllllllllllllllllllllll}C & E & F & M & D & S & S & G & H & V & D & A & L & N & F & L & R & C & I & V & V & D & V & S & N & R & L & F & L & R\end{array}$

ATTCCCATCAATGAGAAAGACTTGCTAGTGAAGATCCACAAATACTTTGACACTTGGCAAACAGTGCTCATCCAGCCAGACATTTTTTTC

$\begin{array}{llllllllllllllllllllllllllllllll}I & \mathrm{P} & I & \mathrm{~N} & \mathrm{E} & \mathrm{K} & \mathrm{D} & \mathrm{L} & \mathrm{L} & \mathrm{V} & \mathrm{K} & \mathrm{I} & \mathrm{H} & \mathrm{K} & \mathrm{Y} & \mathrm{F} & \mathrm{D} & \mathrm{T} & \mathrm{W} & \mathrm{Q} & \mathrm{T} & \mathrm{V} & \mathrm{L} & \mathrm{I} & \mathrm{Q} & \mathrm{P} & \mathrm{D} & \mathrm{I} & \mathrm{F} & \mathrm{F}\end{array}$ CATCTAGCCTGGATGTATAAAAAGCATCACCAAGCAGCAAAGGAGCTACAAGAGGAGATGGGGAGGCTCGTGGAGGAAAAGCGGAAAGCC

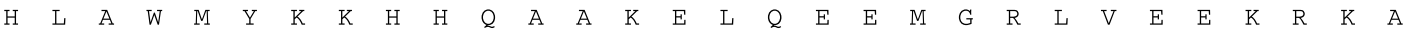
ATCAATGGCATGGAAAAACTGGGAGAGACTGACTTTGCAACCGAGTTGATATTTGCTCAGGATCACGGAGAGATGTCAGAAGATGATGTG $\begin{array}{llllllllllllllllllllllllllllllll}I & N & G & M & E & K & L & G & E & T & D & F & A & T & E & L & I & F & A & Q & D & H & G & E & M & S & E & D & D & V\end{array}$ $\mathrm{P} 1 \rightarrow$ I-helix region

AGGCAGTGTGTGTTGGAGATGGTGATAGCGGCGCCGGACACTCTGTCCATCAGTCTGTTCTTCATGCTGGTGCTGTTGAAGCAGAAGCCA \begin{tabular}{lllllll|lllllllllllllllllllllllllll}
$R$ & $\mathrm{Q}$ & $\mathrm{C}$ & $\mathrm{V}$ & $\mathrm{L}$ & $\mathrm{E}$ & $\mathrm{M}$ & $\mathrm{V}$ & $\mathrm{I}$ & $\mathrm{A}$ & $\mathrm{A}$ & $\mathrm{P}$ & $\mathrm{D}$ & $\mathrm{T}$ & $\mathrm{L}$ & $\mathrm{S}$ & $\mathrm{I}$ & $\mathrm{S}$ & $\mathrm{L}$ & $\mathrm{F}$ & $\mathrm{F}$ & $\mathrm{M}$ & $\mathrm{L}$ & $\mathrm{V}$ & $\mathrm{L}$ & $\mathrm{L}$ & $\mathrm{K}$ & $\mathrm{Q}$ & $\mathrm{K}$ & $\mathrm{P}$
\end{tabular} $\nabla \mathrm{P} 4 \rightarrow$

GAAGTGGAGCAGTGTATACTGCAGGAGATGCGTAATGTCCTAGGTGGACGGGAGGTGGAGCCGGCTGAACTGCAGAAGTTGACAGTGATG $\begin{array}{llllllllllllllllllllllllllllllll}\mathrm{E} & \mathrm{V} & \mathrm{E} & \mathrm{Q} & \mathrm{C} & \mathrm{I} & \mathrm{L} & \mathrm{Q} & \mathrm{E} & \mathrm{M} & \mathrm{R} & \mathrm{N} & \mathrm{V} & \mathrm{L} & \mathrm{G} & \mathrm{G} & \mathrm{R} & \mathrm{E} & \mathrm{V} & \mathrm{E} & \mathrm{P} & \mathrm{A} & \mathrm{E} & \mathrm{L} & \mathrm{Q} & \mathrm{K} & \mathrm{L} & \mathrm{T} & \mathrm{V} & \mathrm{M}\end{array}$ GAGAGTTTTATAAAGGAGTCTTTGCGGTTCCATCCTGTGGTGGATTTCATCATGAGGCGAGCGCTAGACGACGACTTCATCGAAGGCTAC $\begin{array}{llllllllllllllllllllllllllllllll}\mathrm{E} & \mathrm{S} & \mathrm{F} & \mathrm{I} & \mathrm{K} & \mathrm{E} & \mathrm{S} & \mathrm{L} & \mathrm{R} & \mathrm{F} & \mathrm{H} & \mathrm{P} & \mathrm{V} & \mathrm{V} & \mathrm{D} & \mathrm{F} & \mathrm{I} & \mathrm{M} & \mathrm{R} & \mathrm{R} & \mathrm{A} & \mathrm{L} & \mathrm{D} & \mathrm{D} & \mathrm{D} & \mathrm{F} & \mathrm{I} & \mathrm{E} & \mathrm{G} & \mathrm{Y}\end{array}$ Aromatic region

AGGGTGGCCAAAGGGACTAACATCATTCTGAACATTGGCCGGCTGCACAAGAGCGCAGAGTTCTTCCCCAAAGCCAACGAATTCAGCTTG $\begin{array}{llllllllllllllllllllllllllllllll}R & V & A & K & G & T & N & I & I & L & N & I & G & R & L & H & K & S & A & E & F & F & P & K & A & N & E & F & S & L\end{array}$ $\overline{\text { GAGAACTTCGAGAACAATGTGCCGAGTCGTTTCTTCCAGCCATTCGGCTGTGGACCACGTGCCTGTGTGGGGAAGCACATAGCTATGGTC }}$ \begin{tabular}{llllllllllllllllllllllllllllllllll}
$\mathrm{E}$ & $\mathrm{N}$ & $\mathrm{F}$ & $\mathrm{E}$ & $\mathrm{N}$ & $\mathrm{N}$ & $\mathrm{V}$ & $\mathrm{P}$ & $\mathrm{S}$ & $\mathrm{R}$ & $\mathrm{F}$ & $\mathrm{F}$ & $\mathrm{Q}$ & $\mathrm{P}$ & $\mathrm{F}$ & $\mathrm{G}$ & $\mathrm{C}$ & $\mathrm{G}$ & $\mathrm{P}$ & $\mathrm{R}$ & $\mathrm{A}$ & $\mathrm{C}$ & $\mathrm{V}$ & $\mathrm{G}$ & $\mathrm{K}$ & $\mathrm{H}$ & $\mathrm{I}$ & $\mathrm{A}$ & $\mathrm{M}$ & $\mathrm{V}$ \\
\hline
\end{tabular} $\leftarrow \mathrm{P} 2$ ATGATGAAGGCTGTACTGGTGACGGTTCTGTCGCAGTACACGGTGTGTCCTCAGCCCGGCTGTACCGTCAGCACCATCAGGCAAACCAAC \begin{tabular}{llllllllllllllllllllllllllllllll}
\hline M & M & K & A & V & L & V & T & V & L & S & Q & Y & T & V & C & P & $Q$ & P & G & C & T & V & S & T & I & $R$ & $Q$ & $T$ & $N$
\end{tabular}

AACCTCTCACAGCAGCCCATAGAGGAGGACACACAGAGCCTGGCCATGAGGTTCATACCACGCAAACGCAGCCCAGACAAGCAAtaaaCa $\begin{array}{llllllllllllllllllllllllllllll}N & L & S & Q & Q & P & I & E & E & D & T & Q & S & L & A & M & R & F & I & P & R & K & R & S & P & D & K & Q\end{array}$ $\longleftarrow \mathrm{P} 6$

gcctctggattgggaagacatcattcccatcgagtgcagcagggttgcaataattatgactatgttgcaacctcatttttttattctctc cgtcttttcaatctgactacgtgactcaataatttgtggcaaaacgcagatcaagagaaaaagaggacttggaaaattaaacaactaaag gtaacatggtttgaaactagtgaataattaataattaaatatttcatttttgtgaaaaaaaccccccccccccccatcatattattatgc ttagactattatggtataaagtgttagaaaacaagaaacctggaattttttttatgttctaacgtgaatatgtggtttggttagtgtac acgtggtggtagtgtttctcctacctacagcacaaatctgctacatctagaacaatactctatattttgaacttgttagtgaaattatcc agaatataacaaacatgttttcttgcatactacacgcacctgttttaagaaatctactcatgtctgtcatcagtaataaaccaccagta gtaattattattatttttaaatggtaacataactcacttgtctgcgtatatagtgtttatagcgtttttataaatatatttcctctaca gttataaaggaagacatggctccttcattaatggtctttcataacaaatactgctgtaattaaaacggtaacaagcaaaaaaaaaaaaa aaaaaaaaaaa 
An amplicon spanning the promoter region and a portion of the ORF of ccCIP19A2 was generated by PCR using 5'-CATTTGGGAGGCGTTGCGCTGGA-3' and 5'-ATCGCGTACGGTCGATTACAGGCATG-3' primers and Pfu Turbo DNA polymerase. The amplicon was $\mathrm{T} / \mathrm{A}$-subcloned and its sequence was confirmed. The DNA product was inserted upstream of a luciferase reporter gene in pGL3-Basic vector (Promega), a promoter-less vector. Several luciferase reporter constructs were generated in a similar manner using DNA products with progressively longer deletions of the upstream portion of the 5'-flanking region. In all constructs, orientation of inserts was verified by direct sequence analysis.

Aromatase-expressing rat pituitary cells, GH4C1 cells (ATCG), were maintained and grown in DMEM containing $17 \cdot 5 \%$ FBS and antibiotics (penicillin and streptomycin) in 24-well tissue-culture plates. Cells were cotransfected with pRL-Null plasmid (a Renilla luciferase reporter plasmid; Promega) and either one of the ccCYP19A2-promoter-luciferase-reporter constructs or an empty pGL3-Basic vector using FuGENE 6 Transfection Reagent (Roche Diagnostic Corp). After transfection, the medium was replaced with new growth medium supplemented with charcoal-stripped FBS and the cells were incubated for $48 \mathrm{~h}$. After incubation, medium was removed and the cellular enzymatic activities of both firefly and Renilla luciferase were sequentially measured with a Dual-Luciferase Reporter Assay System (Promega) following the manufacturer's instructions. The Renilla luciferase activity provided an internal control to monitor transfection efficiency. Firefly luciferase activity was normalized to the Renilla luciferase activity in each well. Three replicates of each experiment were carried out.

\section{Measurement of transcript abundance by real-time quantitative RT-PCR (rtqPCR)}

Total RNA $(1 \mu \mathrm{g})$ was extracted from whole brains that were collected from pond-raised fish throughout the year and from a variety of other tissues (listed in the Results section), and reverse-transcribed using Moloney murine leukemia virus reverse transcriptase (Life Technologies) primed with a clamped oligo(dT) primer. Due to the expected small amount of total RNA isolated from cultured catfish pituitary cells, total RNA was coprecipitated with $4 \mu \mathrm{l}$ polyacryl carrier (Molecular Research
Center, Cincinnati, OH, USA). The preparation of cDNA from pituitaries collected throughout the reproductive cycle has been described by Kumar \& Trant (2004) (Kazoto et al. 2003; 2005). The transcript abundance of the functional form of ccCYP19A2 was measured using a fluorescence-based rtqRT-PCR method and normalized to the abundance of $\beta$-actin (GenBank accession no. AY555575). The rtqRT-PGR assays for ccCYP19A2 and catfish $\beta$-actin have been described elsewhere (Kazeto et al. 2003). The primer/ probe set for ccCYP19A2 was 5'-TGCATGAC TCGGGTTTGGA-3' (forward), 5'-GGCAACATAGT TACTGCTCTTCAGAAC-3' (reverse) and FAM-5'CACTCATTCTAAGGAAGGGATCTGGTGTGTAC G-3'-TAMRA (probe). The forward primer is located on the deleted portion of ccCYP19A2s, thus only the transcripts that give rise to the longer (functional) ccCYP19A2 are detected by this rtqRT-PGR assay. The primer/probe set for catfish $\beta$-actin was 5'-CACGATT GGGAATGAGAGGTT-3' (forward), 5'-TGGAGTTG AAGGTGGTCTCATG-3' (reverse) and FAM-5'-CGA GCTATCGTTCGTGGGTATGGAGTCGT-3'-TAM RA (probe). The transcript abundance for the $\beta$-subunit of luteinizing hormone (LH $\beta$ ) was also measured by rtqRT-PGR in pituitary cells (Kumar \& Trant 2004). The detailed procedures for designing and synthesizing the primer/probe sets, and to validate the rtqRT-PGR assay, have been fully described elsewhere (Trant et al. 2001).

\section{Statistics}

Fold changes in the transcript abundances were subjected to one-way analysis of variance (ANOVA) followed by Fisher's protected least-significant difference (PLSD) post hoc test. Differences were considered significant at $P<0 \cdot 05$.

\section{Results}

\section{Isolation of the cDNAs encoding ccCYP19A2}

PCR-based isolation of cDNAs encoding ccCYP19A2 (GenBank accession no. AF417239) containing the entire ORF were completed with the aid of $5^{\prime}-$ and 3'-RAGE PGRs. The nucleotide sequences of ccCYP19A2 cDNA with the 5'-UTR type 2 (see below) and the deduced amino acid sequence are illustrated in

Figure 1 The nucleotide and deduced amino acid sequences of the ccCYP19A2 cDNA. The target sequences of the primers used in the cloning strategy are shown in boxes in the nucleotide sequence with exception of those of the degenerate primers (P1 and P2) that are shown within the amino acid sequence. The amino acid sequences corresponding to putative structural regions (membrane-spanning region, I-helix, aromatic region and heme-binding region) are designated by an overline. Polyadenylation consensus sequences in the $3^{\prime}$-UTR are underlined. The nucleotide and the corresponding amino acid sequences of the region deleted by the alternative splicing is boxed. The arrowheads mark the identified (first and second sites) or putative intron/exon boundary sites. The asterisks denote the potential translation start sites for the long and short forms of ccCYP19A2. The open reading frames of the forms are composed of 1500 and $1131 \mathrm{bp}$, respectively. 
Fig. 1. The length of the nucleotide sequence of ccCYP19A2 was $2533 \mathrm{bp}$ and the lengths of the 5'-UTR, ORF (designated ccCYP19A2) and 3'-UTR were 294 bp, 1500 bp encoding 500 amino acid residues and $739 \mathrm{bp}$, respectively. A shorter form of ccCrP19A2 (designated ccCYP19A2s) was also isolated in which the region (bp 45-289) downstream of the translation start codon (ATG) was alternatively spliced out. The deleted nucleotide sequence encodes a portion of exon 4 and the entire exon 5. Furthermore, this alternative splicing resulted in a frame shift; thus the nucleotide sequences upstream of exon 5 would not be translated appropriately. However, there is a translation start codon $81 \mathrm{bp}$ downstream of the deleted portion and therefore an ORF of $1131 \mathrm{bp}$ (potentially encoding a 378-amino acid protein) was identified. The 3 '-UTR contained multiple consensus polyadenylation signals, one AATAAA and three ATTAAA, located 12, 175, 487 and 535 nucleotides upstream from the poly $\left(\mathrm{A}^{+}\right)$tail.

The amino acid sequence of ccCYP19A2 shared 62\% identity with the ovarian form of the catfish P450 aromatase (CYP19A1; Trant 1994). When compared with other fish CYP19A2 forms (Tchoudakova \& Callard 1998, Kishida \& Callard 2001, Kwon et al. 2001, Valle et al. 2002), ccCYP19A2 was $67-72 \%$ identical. Moreover, three putative functional domains identified in mammalian CYP19 forms, the I-helix, aromatasespecific conserved region and the heme-binding region, were significantly more identical $(97,83$ and $100 \%$ respectively) than the rest of the predicted CYP19A2 protein from zebrafish.

\section{Identification and characterization of multiple $5^{\prime}$-UTRs of CCCYP19A2}

Sequence analysis of $5^{\prime}$-terminal regions of 15 clones generated by $5^{\prime}$-RAGE PGRs segregated the $5^{\prime}$-UTR into three groups. In order to examine the structural relationship between the 5'-UTRs and the gene, an upstream primer was designed using the sequence information of these clones and was used for PCRs along with a downstream primer located in the ORF. A schematic illustration of the structural relationship between the 5'-UTR and the corresponding region of the gene is shown in Fig. 2 (see Fig. 6, below, for the specific sequence information). The 5'-UTR type 1 is the least complex form: the UTR is $390 \mathrm{bp}$ in length and is composed of a portion of intron 2 (69 bp), exon 3 (171 bp), intron 3 (96 bp) and a portion of exon 4 (54 bp) with the remaining $136 \mathrm{bp}$ of exon 4 serving as the beginning of the translatable region. The $5^{\prime}$-UTR type 2 is the spliced form of the type 1 : intron 3 is completely spliced out and the size of the UTR is $294 \mathrm{bp}$ in length. Interestingly, the third form of the $5^{\prime}$-UTR designated as type 3 spans 4 exons. The first, second and third exons of the ccCYP19A2 gene comprise 96, 33 and $171 \mathrm{bp}$, respectively, of 5'-UTR type 3 . The

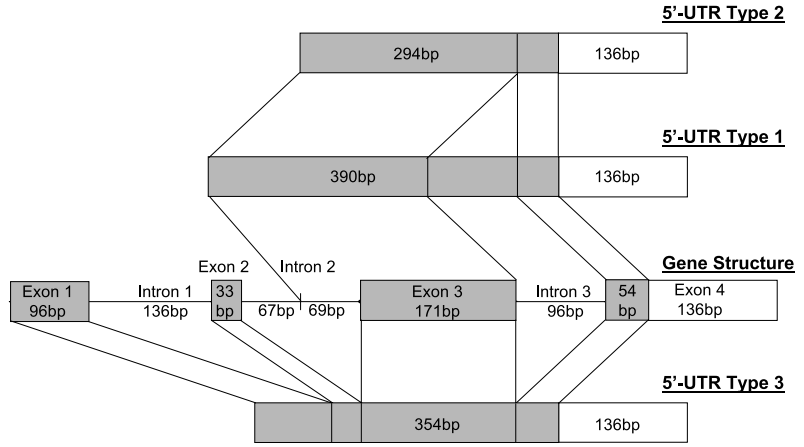

Figure 2 Structural relationship between the $5^{\prime}$-UTRs and the gene of ccCYP19A2. The translated coding region and the untranslated regions are represented by the open and shaded boxes.

structure of exon 4 is the same as that in type 1 and 2 . All the nucleotide sequences of the intron/exon boundary sites were consistent with the classical GT/AG rule (Breathnach \& Chambon 1981) involved in the recognition of intron splice site.

\section{Enzymatic activity of ccCYP19A2 cDNAs expressed in cos-7 cells}

Recombinant ccCrP19A2 expressed in COS-7 cells catalyzed the conversion of androstenedione into estrone. Approximately $15 \%$ of the androstenedione $(30 \mathrm{ng} / \mathrm{ml})$ was converted into estrone $(4 \cdot 42 \pm 0.29 \mathrm{ng} / \mathrm{ml})$ in $3 \mathrm{~h}$ of incubation and over $30 \%(10.58 \pm 0.67 \mathrm{ng} / \mathrm{ml})$ in $10 \mathrm{~h}$. In contrast, no activity was detected in COS-7 cells expressing ccCYP19A2s. Mock control groups did not exhibit any aromatase activity. Transfection efficiency in all experimental groups was confirmed to be consistent by determining firefly luciferase activity in the transfected cells.

\section{Tissue-specific expression of the ccCYP19A2 gene}

Tissue-specific distribution of ccCYP19A2 transcript (the one that encodes the functional enzyme) was determined by rtqRT-PCR (Fig. 3). The transcript for ccCIP19A2 was expressed predominantly in parts of the brain (the telencephalon and hypothalamus), pituitary and area surrounding the ventral aorta. In fish, this is the tissue that includes the thyroid follicles in fish. The transcript was also detected at lower levels in other parts of the brain: cerebellum, diencephalons (without the hypothalamus) and hindbrain. Expression in the intestine, liver and gonads was barely detectable.

\section{Seasonal expression of the ccCYP19A2 gene in brain and pituitary}

Detailed descriptions of the gonadosomatic index of the fish and water temperature have been reported 


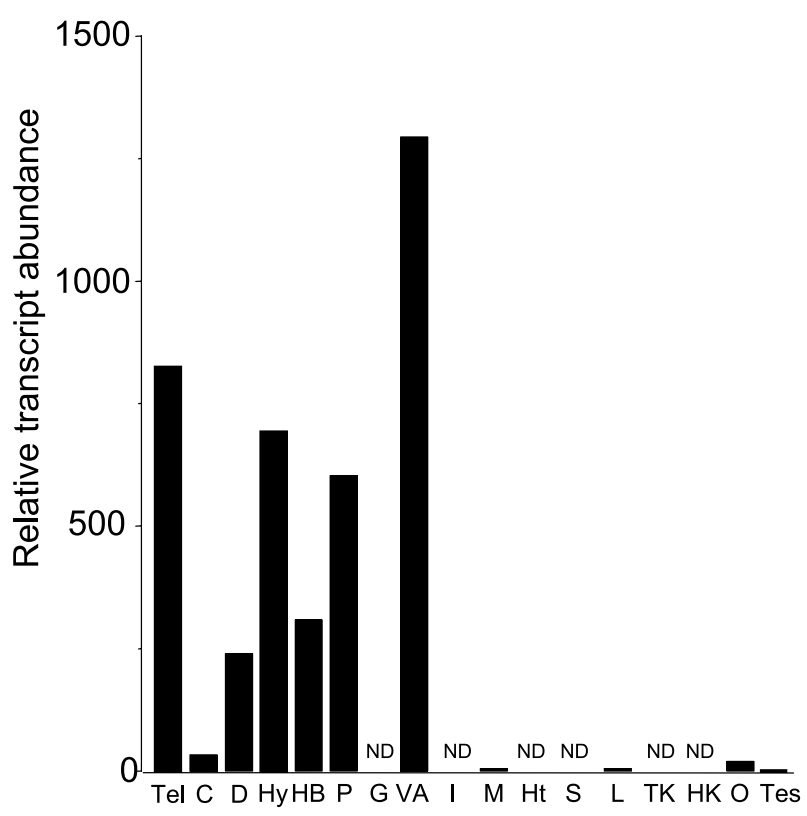

Figure 3 Tissue distribution of the ccCYP19A2 transcript that gives rise to a functional aromatase. The transcript abundance of ccCYP19A2 was determined by rtqRT-PCR analysis and normalized to the abundance of $\beta$-actin transcript. The values are expressed as a fold change in abundance relative to the values in the testis which represents the lowest detectable expression level. Tel, telencephalon; C, cerebellum; D, diencephalon except for hypothalamus; Hy, hypothalamus; HB, hind brain; P, pituitary; G, gill; VA, ventral aorta; I, intestine; $M$, muscle; Ht, heart; S, spleen; L, liver; TK, trunk kidney; HK, head kidney; O, ovary; Tes, testis.

elsewhere (Kumar et al. 2000). Briefly, the gonadosomatic index showed the lowest value in the summer and gradually increased from October to mid-spring. The values rapidly increased from April and peaked around the end of June, prior to the time of spawning (early to mid-July). Using traditional RT-PCR analysis the abundance of the truncated form of ccCrP19A2 (ccCIP19A2s) was relatively stable in the brain during the reproductive cycle whereas the transcript abundance of the active form, ccCYP19A2, increased (data not shown). Owing to the lack of a dynamic pattern of expression and the lack of activity of the encoded protein, only the long transcript of ccCYP19A2 was quantified in the brain and the pituitary by rtqRT-PCR. The abundance of ccCYP19A2 transcript in the brain slightly decreased in late summer, remained low through January and gradually increased in March (early to mid-vitellogenic growth phase). The transcript abundance acutely increased in late June, prior to the anticipated time of spawning, and thereafter decreased precipitously (Fig. 4). The seasonal fluctuation of ccCYP19A2 transcript abundance in the pituitary was similar to that seen in the brain. The expression of the gene rapidly increased around the time of spawning and decreased to the basal level immediately after the spawning period (Fig. 4).

\section{In vitro gene regulation and involvement of ccCYP19A2 in LH $\beta$ gene expression in primary cultured pituitary cells}

Both $\mathrm{E}_{2}$ and testosterone (down to $0.3 \mathrm{nM}$ ) significantly increased the transcript abundance of both ccCTP19A2 and LH $\beta$ genes (Fig. 5). To determine whether testosterone itself modulated the gene expression of ccCYP19A2 and LH $\beta$, cells were incubated with both testosterone and an aromatase inhibitor, ATD. ATD blocked the stimulatory effects of testosterone on ccCIP19A2 and LH $\beta$ transcription (Fig. 5).

\section{Structure of the $5^{\prime}$-flanking region of the ccCYP19A2 gene}

The 5'-terminus and the 5'-flanking region of the ccCrP19A2 gene (1648 bp; GenBank accession no. AY780360) were amplified by a GenomeWalker PCR using specific primers located in exon 4 of the gene (Fig. 6). The full length of the 5'-UTRs were putatively determined by sequence analysis of $5^{\prime}$-RACE amplicons. A TATA box was identified within $30 \mathrm{bp}$ of the end of the $5^{\prime}$-UTR type 1 and 2 whereas there is no TATA-like consensus sequence in the $5^{\prime}$-flanking area of the 5'-UTR type 3. The 5'-flanking region of the ccCYP19A2 gene contained the consensus sequences of a palindromic ERE, a former half ERE and three half AREs.

\section{Functional analysis of the $5^{\prime}$-flanking region of the ccCYP19A2 gene}

The transcriptional activity of the promoter of the ccCTP19A2 gene was determined in a rat $\mathrm{P} 450$ aromatase-expressing cell line (GH4C1 cells) transfected with several deletion mutants of the $5^{\prime}$-flanking region of the gene fused upstream to the luciferase reporter gene in the pGL3-Basic vector. Transient transfection of the deletion constructs of the 5'-flanking region into GH4C1 cells resulted in substantial increases, up to 7 -fold, in luciferase activity compared with a promoter-less pGL3-Basic vector. The highest transcriptional activity was observed in the reporter construct containing the $-1214 /+442, \quad-716 /+442$ and $-687 /+442$ bp regions (Fig. 7). The transcriptional activity partially decreased when the 5'-flanking region was deleted up to the $-116 \mathrm{bp}$ position. Further deletion up to the -46 bp position resulted in a complete loss of promoter activity. 


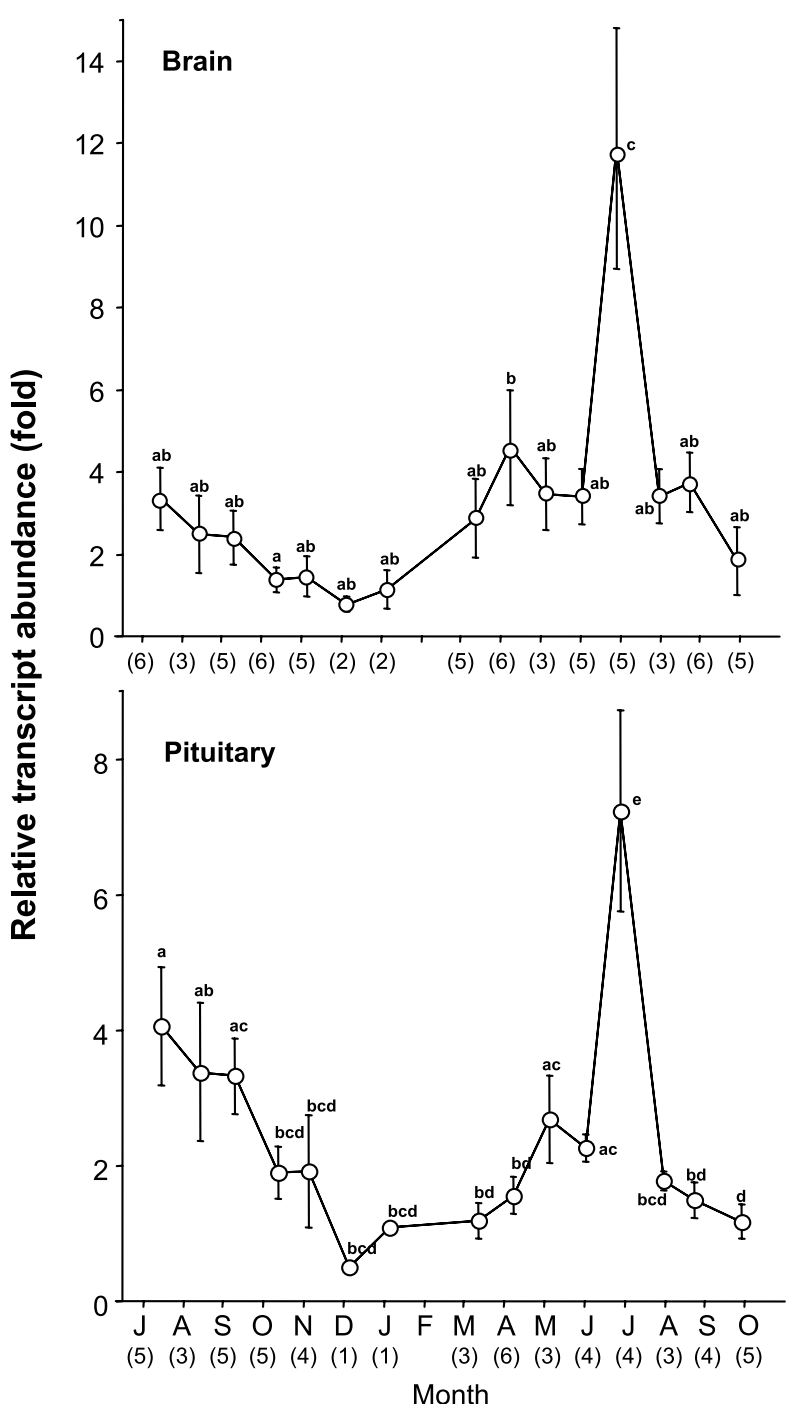

Figure 4 Seasonal fluctuations in transcript abundance of cCCYP19A2 in the catfish brain and the pituitary glands during a complete reproductive cycle. Abundance of ccCYP19A2 transcript was determined by rtqRT-PCR analysis. The data were normalized to $\beta$-actin transcript abundance and expressed as a fold change relative to the mean of November 1996 for the brain and to the mean of October 1997 for the pituitary, which represent the lowest values calculated from a significant number of samples. The results represent means \pm S.E.M. The numbers in parentheses below the month labels are sample sizes. Different letters indicate statistical significant differences between means $(P<0.05)$.

\section{Discussion}

Due to recent intensive cloning studies of CYP19A2 cDNAs from a variety of teleost species (Tchoudakova \& Callard 1998, Kishida \& Callard 2001, Kwon et al. 2001, Valle et al. 2002, Blazquez et al. 2004) there is increasing evidence that the teleost genome contains at least two

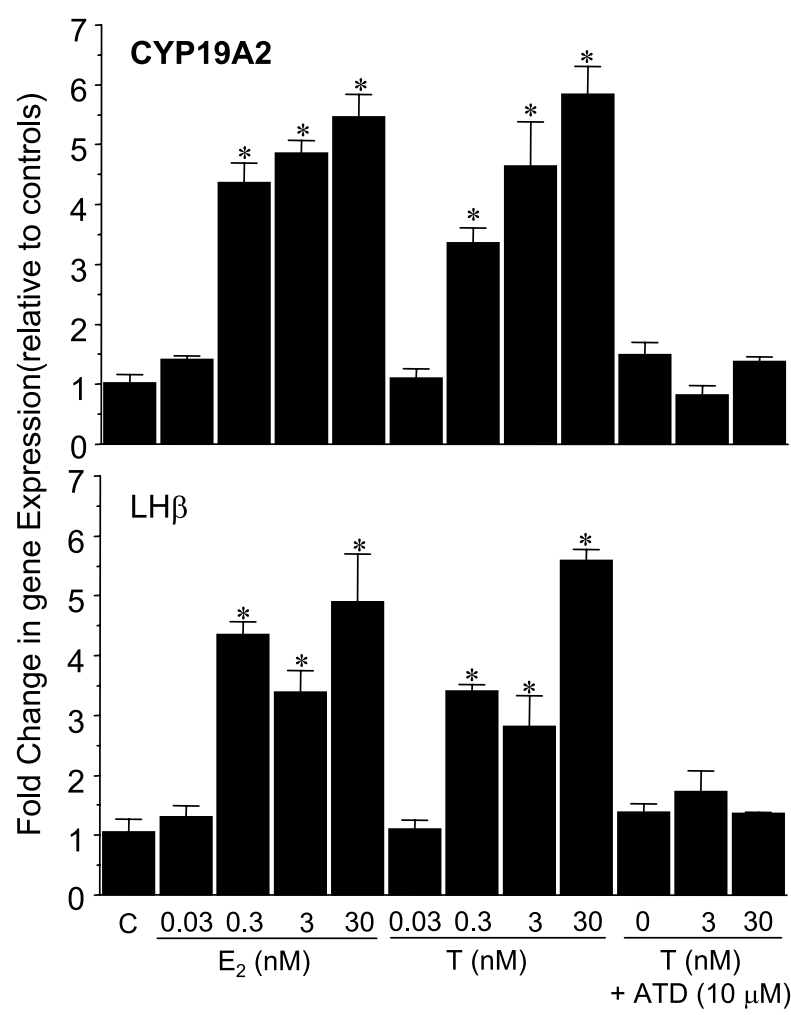

Figure 5 Hormonal regulation of the gene expression of ccCYP19A2 and LH $\beta$ in catfish pituitary cells. Catfish pituitary cells were primary cultured in the presence of either $E_{2}$, testosterone $(T)$ or a combination of testosterone and the aromatase inhibitor ATD $(10 \mu \mathrm{M})$. The quantification of the transcript abundance of ccCYP19A2 and LH $\beta$ genes were determined by rtqRT-PCR analysis and normalized to the abundance of $\beta$-actin transcript. The values are expressed as a fold change in abundance relative to the means in the control group.

CYP19 loci, CYP19A1 and CYP19A2, encoding two distinct $\mathrm{P} 450$ aromatases that are expressed differentially in ovary and neural tissues. In contrast, it has been well demonstrated in almost all non-teleost vertebrates, with the notable exception of the pig (Graddy et al. 2000), that the CIP19 gene is present as a single-copy gene in the genome (Simpson et al. 1997). However, until this study there were no reports describing CIP19A2 in Siluroidei fish (the catfishes, which are a richly studied and intensively cultured taxon of teleost species), although the isolation and characterization of CYP19A1 has been fully described in channel catfish (Trant 1994).

In the present study, the cDNAs encoding the second form of channel catfish P450 aromatase, ccCYP19A2, were cloned from the brain and characterized. Interestingly, two distinct ccCYP19A2 proteins are predicted, ccCYP19A2 and ccCYP19A2s; ccCYP19A2s lacks the first 122 amino acid residues of ccCYP19A2. These truncated residues make up the membranespanning region which are encoded by exons 4 and 5 . 
$-1214$

- 1241 AGGGGGGCCTCGGTCACATTTTAATGCCATTTGGGAGGCCTTGCCCTGGAAAAGTTTGGGAACCCCTGCACTAAATTATA

-1161 CCAGTGGTGGCTTGGCGGTTAAGGCTCTGGGTTACTGATCAGAAGGTCGGGGGTTCAAGCTCCAGCACTGCCAAGCTGTT

-1081 GGGCCCTTAACTCTCTCTGCACCAGGGGTGCTGACCCTGTGCTCTGACCCTAACTTCCTGGCATGCTGGGGAAGAAAAGA

- 1001 ATACATCACTGTATATGTGTACGTGTGATCAATAACGACCCATTATCAAATCCGTGACTTTGAAGAAGAAAAAACAAAAC

-921 AAAAACATTACTCATTTCTGTCATTTGTGTTGAAACTTGCCCATACTGCTGTATACGTTCATATGCTATCAAGACATACA

- 841 GTGTAAGCAATGCCAAAAATAACAGATACTGTGATAGGAAGAGTAACAAAAGGCCCGGCAACAAGCACCAGTGCTGTAAT

$\begin{array}{cccc}-761 & -716 & \text { ERE } & -687 \\ 1\end{array}$ ARE-half

- 681 AAAAGCCCTTTCAGATGATGGATTAGAGAGGGTGTATAGAACAAAGACAAAATTAAATGGGGGAAGAAAAAAAAAAAACA

-601 ACAACAACAACAAAAAAAACCCCACTAAAGTGAAAAGTGCACCAAAATACGCCACATGTGACAGTGATTCTTCGCTTCGT ARE-half

-521 TTCCTTCTTTCATGTG TGTTCTGTTCAAAACTGGACAACAAGCAAAAACGTCTGGATTTTCAATGGCGCTTCACATGCAC

-441 AAGTAAGGCCTGTATCTAAGCAACAGACAGATTTAAAAGGCTTGCAAACCTTTTTCTTTTTTTTTTTTTCAGTCCTGAAA

-361 GAAAAAACAAAACAAAACAGTGATTTAAAACCGATCAGGTTTAAAATGAGGAGAGCCCGCAAACTTCAGCCAGATCCACC

-281 ACAGGCAGTGTAGAGGATTCTTCAACTTTCATCTAACATAACGACgtgagtatatatcactatact ERE-half ARE-half

-201 tcctagtctttatcttatatcattttcataaatcgcaattactgagaagattttaggtcalgctaaatgttcttctttga

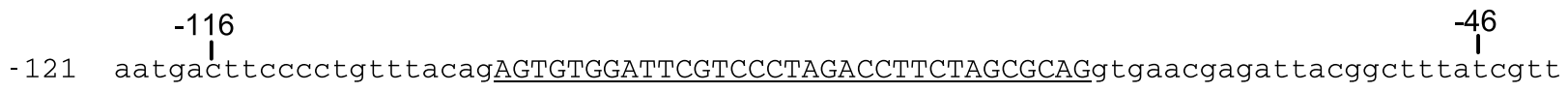
TATA ${ }^{1} \longrightarrow$ The $5^{\prime}$-UTR type 1 and 2

-41 tcggtaacatctgcctgtatattaaagadttttgcacaaaaccttcacacaaacaagacactcaaggocctcttagtcta

40 ctttagacaggtttettttctttcagGATTGTTTTGACTGTTCCAATAGCACAAAGCCTTTGATTTGAAGGACTTTA

120 TAAATTGGATGGCTGCCTGCCAAATCTCTTCAAATCCCCCTTCTTTTCAAGGACCACTTCATGTGCTGTCAAGAAGAAGT

200 ACATTAATATAAGCCAGAAGAGAAACGGCGAGAAATCCAGgtt tactctgacgctaagatctactcatcagagatt

280 agatccgactcacagtctaacgtttattgaaccggtgcttttcatttttgtcatagTGTGAGGAGTCGTTTGGCTCAGGT

360 GGTTTAAGTCAATCTTCACGGAGTTTCAGGATGGAGTTACAGAACGTGTCTGATGTCATGGCTGTAATGGAGGGTAGGGG

Figure 6 Nucleotide sequence and structural features of the $5^{\prime}$-terminus and $5^{\prime}$-flanking regions of the ccCYP19A2 gene. Sequences of putative cis-acting elements of interest are boxed and labeled. Transcribed sequences in the three types of the $5^{\prime}$-UTRs are underlined. Sequences of introns 1-3 are indicated in lower case. All numbering is relative to the putative transcription initiation site for the $5^{\prime}$-UTR types 1 and 2 , designated -1 . 


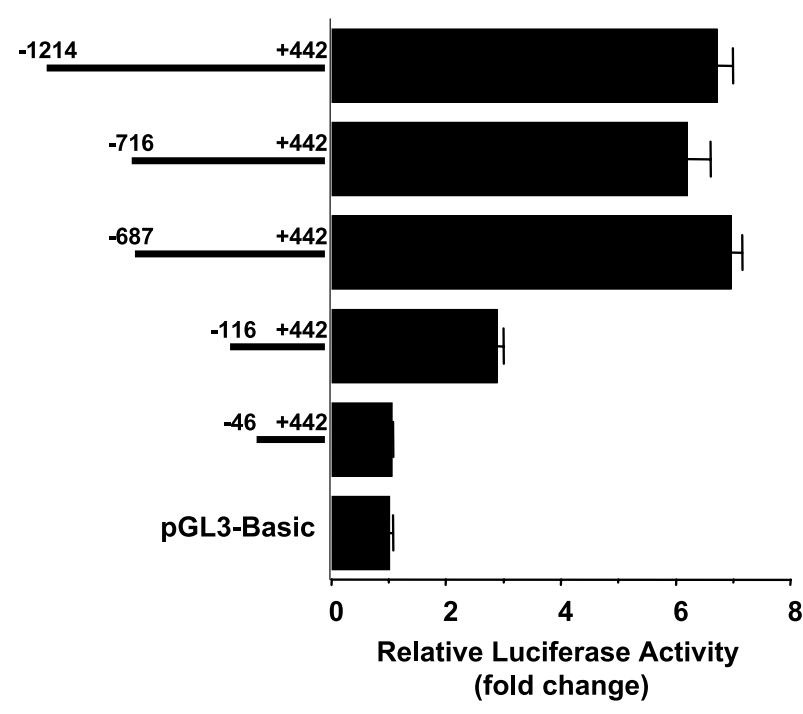

Figure 7 Promoter analysis of the $5^{\prime}$-flanking region of the cCCYP19A2 gene was conducted in cultured GH4C1 rat pituitary cells. Luciferase reporter plasmids containing serially truncated protions of the $5^{\prime}$-flanking region of the ccCYP19A2 gene or empty pGL3 vector was cotransfected with a Renilla luciferase reporter gene, pRL, into GH4C1 cells. Firefly luciferase activities were normalized to Renilla luciferase activities.

The remaining nucleotide sequences are the same in the two forms, and therefore these forms appear to be derived from alternative splicing of the same gene. Two forms of CYP19A2, named form I and II, were also found in rainbow trout brain and form II lacks the first 32 amino acids of form I although it remains unknown whether both of these forms are derived from the same gene or if the truncated form is catalytically active (Valle et al. 2002). Like catfish, an alternative aromatase transcript lacking the initial coding exons 2 and 3 (corresponding to exons 4 and 5 in the ccCYP19A2 gene) has been identified in mammalian brain (Kato et al. 1997, Roselli \& Resko 2001). The truncated form of the recombinant human aromatase was not functional using an 'in cell' assay system although the truncated enzyme was active when reconstituted in vitro with its redox partner, NADPH-cytochrome $\mathrm{P} 450$ reductase (Kao et al. 1999). It was not determined whether the activity of the truncated form of the catfish aromatase can be resurrected in a reconstituted system. More importantly, the significance (if any) of these alternative transcripts or the potential resultant proteins is unknown. It is interesting that the alternative splicing of CYP19 genes in the brain has been maintained in the vertebrates despite the evolutionary distance of the genes.

Three types of $5^{\prime}$-UTR, types 1,2 and 3 , were identified and characterized by comparing those sequences with the structure of the corresponding genomic region. Type 1 is an unprocessed $5^{\prime}$-UTR showing the same structure as the corresponding region of the gene whereas the $5^{\prime}$-UTR type 2 is identical to type 1 except intron 3 (96 bp) is spliced out. In zebrafish (Kazeto et al. 2001) and goldfish (Tchoudakova et al. 2001) the $5^{\prime}$-terminus of the CYP19A2 gene possesses an untranslated exon 1 and an intron (intron 1) and only the transcript without intron 1, namely the spliced form of the 5'-UTR, has been identified. Furthermore, similar structural features have been demonstrated in the brain transcript of CYP19 in human (Honda et al. 1994) and the Atlantic stingray (Ijiri et al. 2000), in which there is a single CRP19 gene in the genome. Therefore, the 5'-UTR type 2 of ccCYP19A2 appears to be a typical form of the 5'-UTR of the brain-specific CYP19 transcript. In contrast, three untranslated exons were identified in the $5^{\prime}$-UTR type 3 of ccCYP19A2, which is the first time this has been demonstrated in any vertebrate. These structural differences of the $5^{\prime}$-UTR may affect the translatability of the transcript and/or the transcriptional activity of each type of transcript driven by the different $5^{\prime}$-flanking region of the gene.

Tissue-specific gene expression of the functional transcript of ccCYP19A2 was examined by rtqRT-PCR analysis. The brain and the pituitary were the major sources of the transcript as demonstrated in other species of teleost (Gelinas et al. 1998, Menuet et al. 2003, Goto-Kazeto et al. 2004) with the telencephalon and hypothalamus expressing the CYP19A2 gene most dominantly. In situ hybridization analyses illustrated high expression of the CYP19A2 gene in the ventral region of the telencephalon and hypothalamus in zebrafish (Goto-Kazeto et al. 2004), rainbow trout (Menuet et al. 2003) and plainfin midshipman (Forlano et al. 2001). Therefore this regional expression pattern of CIP19A2 in the brain appears to be common in teleost fish.

The tissues surrounding the ventral aorta (the site for thyroid follicles in bony fish) was also identified as a novel site for CYP19A2 expression in catfish. The high level of gene expression in the ventral aorta region was confirmed in two additional female catfish by rtqRT-PCR analysis and further by a conventional RT-PCR reaction using a different set of primers (data not shown). CYP19 expression was demonstrated in the thyroid gland of humans (Dalla Valle et al. 1998). It has been established in mammals that $\mathrm{E}_{2}$ enhances the expression of the $\operatorname{tg} b$ gene that controls the synthesis of thyroglobulin (del Senno et al. 1989) and modulates the proliferation and function of thyrocytes (Banu et al. 2002, Filipovic et al. 2003). Although not studied, $\mathrm{E}_{2}$ may play a role in thyroid function in teleost and ccCYP19A2 may contribute significantly to the regional $\mathrm{E}_{2}$ concentration within the area of the thyroid follicles, especially during periods when systemic $\mathrm{E}_{2}$ titers are low. Thyroid follicles would be a possible source for the ccCYP19A2 transcript; however, this region is comprised of multiple tissue types, including blood vessels, nerves, 
connective tissues and potentially the thymus. The specific site for ccCYP19A2 transcript in the tissues surrounding the ventral aorta remains to be established.

The seasonal changes in the transcript abundance of ccCIP19 in the brain and the pituitary had a similar pattern of expression in that transcript abundance dramatically increased prior to spawning and quickly decreased thereafter. More importantly, the patterns of brain and pituitary expression of the ccCYP19A2 gene and the three subunits of pituitary gonadotropins (glycoprotein- $\alpha$, follicle-stimulating hormone $\beta$ and LH $\beta$ ) were determined simultaneously in the same tissues (Kumar \& Trant 2004). This is the first report to compare CYP19A2 transcript abundance with those of the gonadotropin subunits from any vertebrate.

It should be noted in this study of the seasonal changes in expression that there are some time points with very small sample sizes $(n \leq 3)$; however, the transcript abundance was relatively constant, with a small standard error. Even though it would be best to have the confidence afforded by a larger number of samples, the lack of variation in these data permits some degree of conjecture as to the biological significance of the seasonal changes in the expression of ccCYP19A2.

The hypothalamic area of the brain, one of the main sites for CYP19A2 expression, is also a major site for the expression of type I GnRH. GnRH plays an important role in gonadal maturation through the induction of gonadotropin expression and secretion in vertebrates, including teleosts (Senthilkumaran et al. 1999, Dubois et al. 2001a). It was also demonstrated in African catfish, Clarias gariepinus, that testosterone (an aromatizable androgen), but not 11-ketotestosterone (a nonaromatizable androgen), enhanced gene expression of type I GnRH in the brain (Dubois et al. 2001b). Considering these findings together with the preovulatory induction of the ccCYP19A2 gene expression in the catfish brain, CYP19A2 could be an important agent in the regulation of type I GnRH in catfish. Furthermore, the preovulatory induction of the ccCYP19A2 gene in the pituitary correlate well with the seasonal dynamics of LH $\beta$ subunit gene expression (Fig. 4; Kumar \& Trant 2004), thus suggesting the involvement of CYP19A2 in LH $\beta$ gene regulation. It should be noted that the channel catfish is the first vertebrate species in which CYP19 expression in the pituitary gland has correlated positively with the reproductive cycle.

Transcription of ccCYP19A2 was strongly enhanced in primary cultures of catfish pituitary cells prepared from reproductively active (post-vitellogenic but prior to the spawning period) fish when exposed to exogenous $\mathrm{E}_{2}$ and testosterone; however, the regulatory potential of testosterone was abolished by an aromatase inhibitor. ATD itself (the results for $0 \mathrm{nM}$ testosterone plus $10 \mu \mathrm{M}$ ATD; Fig. 5) did not show any significant effect on ccCYP19A2 or LH $\beta$ transcription. These findings indicate that testosterone itself has little or no effects on CYP19A2 gene expression in the catfish pituitary and the upregulation induced by testosterone largely depends on its aromatization to $\mathrm{E}_{2}$. However, Northern blotting revealed that in vivo exposure of reproductively inactive (post-spawning) goldfish to $\mathrm{E}_{2}$ or testosterone for 3 weeks showed no alteration in CIP19A2 transcript abundance in the pituitary (Gelinas et al. 1998). This notable difference is likely due to the use of fish at different reproductive extremes; reproductively active versus inactive. We would suspect that the responsiveness of the pituitary to $\mathrm{E}_{2}$ would vary with the reproductive status of fish throughout the reproductive season. In fact, it was recently reported in African catfish that the transcript abundance of the estrogen receptor- $\alpha$ increased in the pituitary during reproductive development (Teves et al. 2003).

Even though the cellular localization of the transcript and/or enzymatic activity of CYP19A2 has not been definitely established, either the gonadotrophs (Melamed et al. 1999) or somatotrophs (Callard et al. 1988) are likely to be the cellular source of this enzyme. In either case, the positive correlation of the hypophyseal expression of CYP19A2 and LH $\beta$ during a reproductive season (Fig. 4; Kumar \& Trant 2004) and regulation of LH $\beta$ by $\mathrm{E}_{2}$ (but not testosterone) in primary cultures of pituitary cells (Fig. 5) indicates that the CYP19A2 gene plays a role in LH $\beta$ and reproductive endocrinology. The action of $\mathrm{E}_{2}$ on $\mathrm{LH}$ production has been demonstrated in male African catfish (Rebers et al. 2000). Interestingly, the transcript abundance of the other two subunits of catfish gonadotropins (glycoprotein hormone $\alpha$ and follicle-stimulating hormone $\beta$ ) and growth hormone was not significantly altered by steroid treatment (data not shown). Therefore, it is evident in the channel catfish pituitary that CYP19A2 is an important factor during this reproductive stage (post-vitellogenic but prior to spawning) by specifically regulating LH $\beta$ gene expression through the aromatization of testosterone.

The 5'-flanking region of the ccCrP19A2 gene contains ERE-related consensus sequences, as would be predicted by the ability of $\mathrm{E}_{2}$ to upregulate CYP19A2 expression in the pituitary. Upregulation of transcription or activity of CYP19A2 by estrogen has been well established in the brain of adult (Gelinas et al. 1998) and juvenile fish (Menuet et al. 2005). Furthermore, ERErelated sequences, including a highly conserved palindromic ERE, has been identified in zebrafish (Kazeto et al. 2001) and goldfish (Tchoudakova et al. 2001). These findings strongly suggest that estrogen would be a comprehensive regulator for the expression of CYP19A2 gene in teleosts and the effects of estrogen on CYP19A2 expression would be, at least in part, dependent upon direct transcriptional modulation of the gene. The 5'-flanking region of the CYP19A2 gene in zebrafish and/or goldfish showed other consensus sequences for 
transcriptional factor-binding sites potentially related to reproductive physiology or endocrine disruption, such as CRE and AhR/Arnt; however, there are no potential binding sites for these transcriptional factors in the 5'-flanking region of the catfish CIP19A2 gene. Therefore, these factors may not be common regulators of the CTP19A2 gene in teleosts even if they are functional regulatory elements in the zebrafish and/or goldfish.

Promoter activity of several selected segments of the 5 -flanking region of ccCYP19A2 gene was quantified by a luciferase reporter assay system. Even though the use of catfish pituitary cells in primary culture would be the most relevant model for promoter analysis of the ccCYP19A2 gene, primary cultures of catfish pituitary cells resisted transfection, thereby prompting us to use an aromatase-expressing rat pituitary cell line, GH4C1. The entire 5 '-flanking region of the gene showed strong transcriptional activity in GH4C1 cells and this high transcriptional activity was maintained when the 5'-flanking region was truncated to the $-687 \mathrm{bp}$ position (Fig. 7). Further deletion of the 5'-flanking region caused decreases in the activity and the construct containing a minimal fragment, $-46 /+52 \mathrm{bp}$, of the region did not show any promoter activity. These findings suggest that the sequence from -687 to $-46 \mathrm{bp}$ is critical for the basal promoter activity in catfish pituitary. However, we still cannot rule out the possibility that the basal expression of ccCYP19 in the catfish pituitary is not well reflected by the promoter activity in GH4Cl cells. The promoter structure and the regulation of CYP19 gene in the rat pituitary have not been described.

In conclusion, an active form of CIP19A2, an inactive form (derived from alternative splicing) and multiple 5 '-UTRs were identified in the channel catfish. Furthermore, it was demonstrated for the first time in the pituitary gland that estrogen upregulates transcription of the CYP19A2 gene. The gene expression of CrP19A2 in the catfish brain and pituitary correlates positively with the reproductive status of the ovary. Moreover, in vitro experiments with pituitary cells clearly demonstrated that CYP19A2 is specifically involved in the regulation of the LH $\beta$ subunit gene expression through the aromatization of testosterone. These findings clearly establish that the CIP19A2 gene functions as an important factor for the reproductive endocrinology in teleost through the brain-pituitary-gonadal axis.

\section{Acknowledgement}

We thank Dr Shigeho Ijiri (National Institute for Basic Biology, Okazaki, Japan) for designing and providing degenerate primers (P1 and P2), Dr Ramasamy Sampath Kumar and Dr Rie Goto-Kazeto (Center of Marine Biotechnology, Baltimore, MD, USA) for technical assistance and thoughtful discussion. This is contribution number 05-108 from the Center of Marine Biotechnology. This work was supported by a grant from the USDA (Enhancing Reproductive Efficiency; 00-35203-9105) to J M T. Y K was supported by a fellowship from the Japan Society for the Promotion of Science. The authors declare that there is no conflict of interest that would prejudice the impartiality of this scientific work.

\section{References}

Banu SK, Govindarajulu P \& Aruldhas MM 2002 Testosterone and estradiol differentially regulate TSH-induced thyrocyte proliferation in immature and adult rats. Steroids 67 573-579.

Billard R 1992 Reproduction in rainbow trout: sex differentiation, dynamics of gametogenesis, biology and preservation of gametes. Aquaculture 100 263-298.

Blazquez M \& Piferrer F 2004 Cloning, sequence analysis, tissue distribution, and sex-specific expression of the neural form of P450 aromatase in juvenile sea bass (Dicentrarchus labrax). Molecular \& Cellular Endocrinology 219 83-94.

Breathnach R \& Chambon P 1981 Organization and expression of eucaryotic split genes coding for proteins. Annual Reviews in Biochemistry 50 349-383.

Callard GV, Petro Z \& Tashjian AH Jr 1983 Identification of aromatase activity in rodent pituitary cell strains. Endocrinology 113 $152-158$.

Callard GV, Specker JL, Knapp J, Nishioka RS \& Bern HA 1988 Aromatase is concentrated in the proximal pars distalis of tilapia pituitary. General \& Comparative Endocrinology 71 70-79.

Carretero J, Vazquez G, Blanco E, Rubio M, Santos M, Martin-Clavijo A, Torres JL \& Vazquez R 1999 Immunohistochemical evidence of the presence of aromatase P450 in the rat hypophysis. Cell Tissue Research $295419-423$.

Dalla Valle L, Ramina A, Vianello S, Fassina A, Belvedere P \& Colombo L 1998 Potential for estrogen synthesis and action in human normal and neoplastic thyroid tissues. Fournal of Clinical Endocrinology \& Metabolism 83 3702-3709.

del Senno L, degli Uberti E, Hanau S, Piva R, Rossi R \& Trasforini G 1989 In vitro effects of estrogen on tgb and c-myc gene expression in normal and neoplastic human thyroids. Molecular $\mathbb{E}^{\circ}$ Cellular Endocrinology 63 67-74.

Dubois EA, Zandbergen MA, Peute J \& Goos HJ 2001 a Development of three distinct $\mathrm{GnRH}$ neuron populations expressing two different $\mathrm{GnRH}$ forms in the brain of the African catfish (Clarias gariepinus). Fournal of Comparative Neurology 437 308-320.

Dubois EA, Slob S, Zandbergen MA, Peute J \& Goos HJ $2001 b$ Gonadal steroids and the maturation of the species-specific gonadotropin-releasing hormone system in brain and pituitary of the male African catfish (Clarias gariepinus). Comparative Biochemistry EF Physiology B Biochemistry \& Molecular Biology 129 381-387.

Filipovic B, Sosic-Jurjevic B, Nestorovic N, Manojlovic Stojanoski M, Kostic N, Milosevic V \& Sekulic M 2003 The thyroid C cells of ovariectomized rats treated with estradiol. Histochemistry \& Cell Biology 120 409-414.

Forlano PM, Deitcher DL, Myers DA \& Bass AH 2001 Anatomical distribution and cellular basis for high levels of aromatase activity in the brain of teleost fish: aromatase enzyme and mRNA expression identify glia as source. Fournal of Neuroscience 21 8943-8955.

Gelinas D, Pitoc GA \& Callard GV 1998 Isolation of a goldfish brain cytochrome P450 aromatase cDNA: mRNA expression during the seasonal cycle and after steroid treatment. Molecular $\mathbb{E}^{2}$ Cellular Endocrinology 138 81-93.

Goto-Kazeto R, Kight KE, Zohar Y, Place AR \& Trant JM 2004 Localization and expression of aromatase mRNA in adult zebrafish. General \& Comparative Endocrinology 139 72-84. 
Graddy LG, Kowalski AA, Simmen FA, Davis SL, Baumgartner WW \& Simmen RC 2000 Multiple isoforms of porcine aromatase are encoded by three distinct genes. Fournal of Steroid Biochemistry $\mathbb{E}$ Molecular Biology 73 49-57.

Honda S, Harada N \& Takagi Y 1994 Novel exon 1 of the aromatase gene specific for aromatase transcripts in human brain. Biochemistry \& Biophysics Research Communications 198 1153-1160.

Ijiri S, Berard C \& Trant JM 2000 Characterization of gonadal and extra-gonadal forms of the cDNA encoding the Atlantic stingray (Dasyatis sabina) cytochrome P450 aromatase (CYP19). Molecular E Cellular Endocrinology 164 169-181.

Kao YC, Higashiyama T, Yarborough C, Osawa Y \& Chen S 1999 Functional characterization of 102-amino acid-deleted form of human aromatase ( $\Delta$ 102-aromatase). Steroids $64422-429$

Kato J, Yamada-Mouri N \& Hirata S 1997 Structure of aromatase mRNA in the rat brain. Fournal of Steroid Biochemistry \& Molecular Biology 61 381-385.

Kazeto Y, Ijiri S, Place AR, Zohar Y \& Trant JM 2001 The 5'-flanking regions of CYP19A1 and CYP19A2 in zebrafish. Biochemistry \& Biophysics Research Communications 288 503-508.

Kazeto Y, Goto-Kazeto R, Place AR \& Trant JM 2003 Aromatase (CYP19A2) in zebrafish and channel catfish brains: changes in expression associated with the reproductive cycle and endocrine disrupting chemicals. Fish Physiology \& Biochemistry 28 29-32.

Kazeto Y, Place AR \& Trant JM 2004 Effects of endocrine disrupting chemicals on the expression of CYP19 genes in zebrafish (Danio rerio) juvenile. Aquatic Toxicology 69 25-34.

Khan IA, Hawkins MB \& Thomas P 1999 Gonadal stage-dependent effects of gonadal steroids on gonadotropin II secretion in the Atlantic croaker (Micropogonias undulatus). Biology of Reproduction $6 \mathbf{1}$ $834-841$.

Kishida M \& Callard GV 2001 Distinct cytochrome P450 aromatase isoforms in zebrafish (Danio rerio) brain and ovary are differentially programmed and estrogen regulated during early development. Endocrinology 142 740-750.

Kumar RS, Ijiri S \& Trant JM 2000 Changes in the expression of genes encoding steroidogenic enzymes in the channel catfish (Ictalurus punctatus) ovary throughout a reproductive cycle. Biology of Reproduction 63 1676-1682.

Kumar RS, Ijiri S \& Trant JM 2001a Molecular biology of channel catfish gonadotropin receptors: I. Cloning of a functional luteinizing hormone receptor and preovulatory induction of gene expression. Biology of Reproduction 64 1010-1018.

Kumar RS, Ijiri S \& Trant JM $2001 b$ Molecular biology of catfish gonadotropin receptors: II. Cloning of a follicle stimulating hormone receptor and its seasonal expression in the ovary. Biology of Reproduction 65 710-717.

Kumar RS \& Trant JM 2004 Hypophyseal gene expression profiles of FSH- $\beta$, LH- $\beta$, and glycoprotein hormone- $\alpha$ subunits in Ictalurus punctatus throughout a reproductive cycle. General $\mathcal{E}^{2}$ Comparative Endocrinology 136 82-89.

Kwon JY, McAndrew BJ \& Penman DJ 2001 Cloning of brain aromatase gene and expression of brain and ovarian aromatase genes during sexual differentiation in genetic male and female Nile tilapia Oreochromis niloticus. Molecular \& Reproductive Developments $59359-370$

Lephart ED 1996 A review of brain aromatase cytochrome P450. Brain Research Reviews 22 1-26.

MacLusky NJ \& Naftolin F 1981 Sexual differentiation of the central nervous system. Science $2111294-1302$.

Melamed P, Gur G, Rosenfeld H, Elizur A \& Yaron Z 1999 Possible interactions between gonadotrophs and somatotrophs in the pituitary of tilapia: apparent roles for insulin-like growth factor I and estradiol. Endocrinology 140 1183-1191.

Menuet A, Anglade I, Guevel RL, Pellegrine E, Pakdel F \& Kah O 2003 Distribution of aromatase mRNA and protein in the brain and pituitary of female rainbow trout: comparison with estrogen receptor. Journal of Comparative Neurology 462 180-193.
Menuet A, Pellegrini E, Brion F, Gueguen MM, Anglade I, Pakdel F, Kah O 2005 Expression and estrogen-dependent regulation of the zebrafish brain aromatase gene. Fournal of Comparative Neurology $485304-320$.

Pasmanik M \& Callard GV 1985 Aromatase and $5 \alpha$-reductase in the teleost brain, spinal cord, and pituitary gland. General $\mathbb{E}^{\circ}$ Comparative Endocrinology $60244-251$.

Rebers FE, Hassing GA, Zandbergen MA, Goos HJ \& Schulz RW 2000 Regulation of steady-state luteinizing hormone messenger ribonucleic acid levels, de novo synthesis, and release by sex steroids in primary pituitary cell cultures of male African catfish, Clarias gariepinus. Biology of Reproduction $62864-872$.

Roselli CE \& Resko JA 2001 Cytochrome P450 aromatase (CYP19) in the non-human primate brain: distribution, regulation, and functional significance. Fournal of Steroid Biochemistry $\&$ Molecular Biology 79 247-253.

Senthilkumaran B, Okuzawa K, Gen K, Ookura T \& Kagawa H 1999 Distribution and seasonal variations in levels of three native GnRHs in the brain and pituitary of perciform fish. Fournal of Neuroendocrinology 11 81-86.

Simpson ER, Mahendroo MS, Means GD, Kilgore MW, Hinshelwood MM, Graham-Lorence S, Amarneh B, Ito Y, Fisher CR, Michael MD, Mendelson CR \& Bulun SE 1994 Aromatase cytochrome $\mathrm{P} 450$, the enzyme responsible for estrogen biosynthesis. Endocrine Reviews 15 342-355.

Simpson ER, Zhao Y, Agarwal VR, Michael MD, Bulun SE, Hinshelwood MM, Graham-Lorence S, Sun T, Fisher CR, Qin K \& Mendelson CR 1997 Aromatase expression in health and disease. Recent Progress in Hormone Research 52 185-214.

Tchoudakova A \& Callard GV 1998 Identification of multiple CYP19 genes encoding different cytochrome P450 aromatase isozymes in brain and ovary. Endocrinology $1392179-2189$.

Tchoudakova A, Kishida M, Wood E \& Callard GV 2001 Promoter characteristics of two cyp 19 genes differentially expressed in the brain and ovary of teleost fish. Foumal of Steroid Biochemistry $\mathbb{E}^{\circ}$ Molecular Biology 78 427-439.

Teves AC, Granneman JC, van Dijk W \& Bogerd J 2003 Cloning and expression of a functional estrogen receptor- $\alpha$ from African catfish (Clarias gariepinus) pituitary. Fournal of Molecular Endocrinology 30 173-185.

Tong SK, Chiang EF, Hsiao PH \& Chung B 2001 Phylogeny, expression and enzyme activity of zebrafish cyp 19 (P450 aromatase) genes. Fournal of Steroid Biochemistry E' Molecular Biology 79 299-303.

Toran-Allerand CD 1996 Mechanisms of estrogen action during neural development: mediation by interactions with the neurotrophins and their receptors? Fournal of Steroid Biochemistry \& Molecular Biology 56 169-178.

Trant JM 1994 Isolation and characterization of the cDNA encoding the channel catfish (Ictalurus punctatus) form of cytochrome P450 arom. General \& Comparative Endocrinology 95 155-168.

Trant JM, Gavasso S, Ackers J, Chung B-C \& Place AR 2001 Developmental expression of cytochrome $\mathrm{P} 450$ aromatase genes (CYP19a and 19b) in zebrafish fry (Danio rerio). Fournal of Experimental Zoology $290475-483$.

Valle LD, Ramina A, Vianello S, Belvedere P \& Colombo L 2002 Cloning of two mRNA variants of brain aromatase cytochrome P450 in rainbow trout (Oncorhynchus mykiss Walbaum). Journal of Steroid Biochemistry \& Molecular Biology 82 19-32.

Wallace RA 1985 Vitellogenesis and oocyte growth in nonmammalian vertebrates. In: Developmental Biology, vol 1, pp 127-177. Ed LW Browder. New York: Plenum Press.

Wibbels T, Bull JJ \& Crews D 1991 Synergism between temperature and estradiol: A common pathway in turtle sex determination. Fournal of Experimental Zoology 260 130-134.

Received 12 July 2005

Accepted 6 September 2005 